\title{
Effect of $\beta$-Lactam Antibiotics on Bacterial Cell Growth Rate
}

\author{
By GEORGE N. ROLINSON \\ Beecham Pharmaceuticals Research Division, Chemotherapeutic Research Centre, \\ Brockham Park, Betchworth, Surrey RH3 $7 A J$
}

(Received 31 March 1980)

\begin{abstract}
The effect of penicillins and cephalosporins on the rate of growth of individual cells of Escherichia coli on agar was determined by measurement of cell length using photomicrographs taken at frequent intervals. When exposed to cephalexin or carbenicillin at twice the minimum inhibitory concentration cell division was inhibited but growth in length proceeded at a uniform exponential rate until abruptly terminated by lysis. The rate of growth of such filamentous cells did not differ significantly from that of normal cells grown in the absence of antibiotic. In contrast, exposure to cephaloridine and amoxycillin at twice the minimum inhibitory concentration resulted in a marked diminution in the rate of cell growth, and lysis occurred very much sooner. At concentrations greatly in excess of the minimum inhibitory concentration ( $>100$-fold) cephalexin also resulted in a diminution in the rate of cell growth and this was accompanied by earlier lysis. The significance of these findings is discussed in relation to the mode of action of $\beta$-lactam antibiotics.
\end{abstract}

\section{INTRODUCTION}

When bacterial growth is said to be inhibited by antibiotics, what is usually meant is that the multiplication of a population of cells is sufficiently decreased to prevent growth reaching visible proportions. This could result from an effect on the rate of cell growth, or it could result from the early termination of growth of individual cells, for example by cell lysis, and prior to this event the rate of cell growth might be uninfluenced by the antibiotic. In the case of the penicillins and cephalosporins, the target site is generally believed to be the cell wall, and, more specifically, certain enzymes involved in murein synthesis and hydrolysis (Strominger, 1973; Tomasz, 1979). With certain penicillins and cephalosporins, although cell division in Escherichia coli and other Gram-negative bacilli is inhibited, the cells continue to increase in length giving rise to long filaments which eventually lyse (Gardner, 1940; Greenwood \& O'Grady, 1973). The formation of such filamentous cells clearly involves cell growth but the rate of growth during this process has not been clearly established.

In contrast to the filament formation caused by certain $\beta$-lactams, with other penicillins and cephalosporins lysis of $E$. coli occurs very rapidly and cell elongation is not pronounced (Greenwood \& O'Grady, 1973; Rolinson et al., 1977). However, it has not been established whether or not the rate of cell growth prior to rapid bacteriolysis is influenced by the antibiotic.

Determination of the effect of $\beta$-lactams on bacterial growth by means of viable counts or by turbidimetric methods does not establish whether or not the rate of cell growth is inhibited. Such measurements indicate the growth of the population of cells as a whole but not the rate of growth of the individual members, because as time proceeds the proportion of the population capable of further growth may diminish as a result of the action of the 
antibiotic. Such action may also be rapid and with certain penicillins and cephalosporins lysis of a proportion of cells can be observed as early as 20 min after addition of the antibiotic (Rolinson et al., 1977).

In order to obtain definitive information about the effect of $\beta$-lactams on the rate of cell growth of $E$. coli, measurements of cell length were made from photomicrographs, taken at frequent intervals, of cells growing on agar containing antibiotic.

\section{METHODS}

The strain of Escherichia coli used was NCTC 10418.

Photomicrographs were taken using differential interference contrast microscopy (Nomarski optics). Cells were first grown in Brain Heart Infusion (BHI) broth in shaken culture at $37^{\circ} \mathrm{C}$ and the antibiotic was added during late-exponential phase. A sample of culture was then transferred to a thin layer of agar, also containing the antibiotic, on a microscope slide maintained at $37^{\circ} \mathrm{C}$ on a heated stage. The details of the techniques for cell culture, determinations of minimum inhibitory concentration (m.i.c.), microscopy and photography were as described by Rolinson et al. (1977). Cell lengths were measured with a scale from enlargements projected on a screen and, where necessary, a map measurer was used to follow the course of the filaments. In the case of filaments which grew beyond the boundary of the microscope field, measurements of length could not be continued but the time at which such filaments eventually lysed could be observed and this was recorded.

\section{RESULTS}

Results in Fig. 1 show the growth of four cells from a culture of $E$. coli in the absence of antibiotic; these are representative of a larger number of observations. Commencement of division could generally be observed when the cells were 5 to $6 \mu \mathrm{m}$ in length and when division was complete the daughter cells were usually 3.0 to $3.5 \mu \mathrm{m}$ in length. The mean cell length of the population was $4.5 \mu \mathrm{m}$. Cell length doubling times in 18 observations ranged from 19 to $26 \mathrm{~min}$ with a mean value of $22 \mathrm{~min}$.

Results in Figs 2 to 6 show the effect of cephalexin, carbenicillin, ampicillin, amoxycillin and cephaloridine on increase in cell length when each antibiotic was present at a concentration of $2 \times$ m.i.c. The m.i.c. value for each of these antibiotics for the culture of $E$. coli used was $5 \mu \mathrm{g} \mathrm{ml}^{-1}$ except in the case of cephalexin for which the value was $10 \mu \mathrm{g} \mathrm{ml}^{-1}$. In all the observations on the effect of these antibiotics on the cell no significant change in cell diameter occurred and therefore the term growth is used in this report as being synonymous with increase in cell length.

\section{Effect of cephalexin}

Cephalexin at a concentration of $2 \times$ m.i.c. inhibited cell division completely but growth continued giving rise to filamentous cells. The growth of such filaments proceeded at a uniform exponential rate with a doubling time ranging from 23 to 25 min with a mean of $23.9 \mathrm{~min}$ (Fig. 2). This rate of growth was very similar to that found for normal dividing cells growing in the absence of antibiotic (doubling time $22 \mathrm{~min}$ ). It can also be seen from Fig. 2 that the rate of growth did not change during exposure to the antibiotic but remained constant up to the moment of cell wall rupture which occurred suddenly, resulting in lysis. At the time of lysis the filaments ranged from 60 to $100 \mu \mathrm{m}$ in length. In some cells a localized swelling of the filaments was observed shortly before lysis and cell wall rupture occurred at this region. Lysis occurred 110 to 134 min after addition of the antibiotic.

With cephalexin at $100 \times$ m.i.c., the majority of cells showed a uniform exponential rate of growth with a doubling time ranging from 22 to $26 \mathrm{~min}$ and a mean of $24.4 \mathrm{~min}$. This value does not differ appreciably from the growth rate in the presence of cephalexin at only $2 \times$ m.i.c., or from the growth rate of normal dividing cells. In these cells, too, growth continued at a uniform rate up to the moment of lysis. Lysis occurred from 68 to $176 \mathrm{~min}$ 


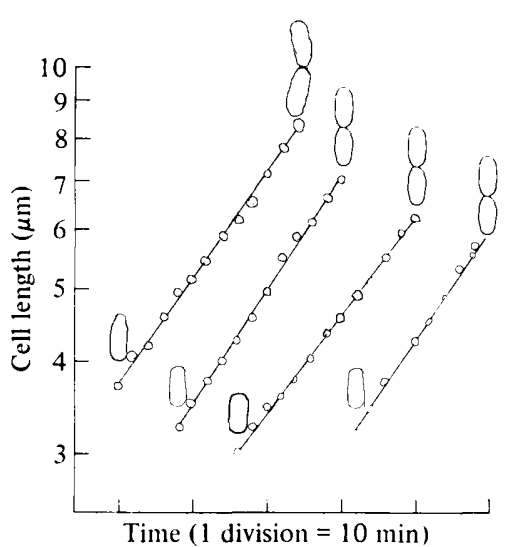

Fig. 1

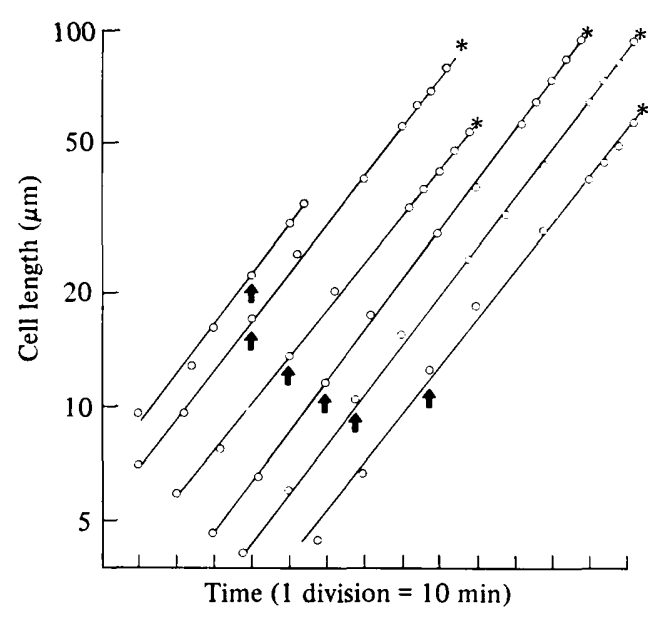

Fig. 2

Fig. 1. Normal growth of $E$. coli in the absence of antibiotic.

Fig. 2. Rate of cell growth of $E$. coli in the presence of cephalexin at $20 \mu \mathrm{g} \mathrm{ml}^{-1}(2 \times \mathrm{m}$.i.c.). The plots for each cell have been displaced in time for clarity and the arrows indicate in each case the time 60 min after addition of antibiotic. * denotes the time of lysis.

after addition of the antibiotic. Although the majority of the cells showed a rate of growth similar to that seen with $2 \times$ m.i.c., a small proportion showed a significantly slower rate of growth with doubling times ranging from 36 to $54 \mathrm{~min}$. In these cells lysis occurred 66 to $121 \mathrm{~min}$ after addition of the antibiotic, and in some cases the rate of growth was also found to diminish prior to rupture of the cell wall.

With cephalexin at $500 \times$ m.i.c., lysis occurred very rapidly. The majority of cells showed wall rupture, or had lysed completely, within $30 \mathrm{~min}$ of the addition of the drug. By this time very little cell elongation had occurred and meaningful measurements of the rate of cell growth over this period were not possible.

\section{Effect of carbenicillin}

In the presence of carbenicillin at $2 \times$ m.i.c., growth proceeded at a uniform exponential rate with a doubling time similar to that of normal dividing cells. Typical results are given in Fig. 3 showing a mean doubling time of $20.7 \mathrm{~min}$. These filaments lysed 130 to $150 \mathrm{~min}$ after addition of the antibiotic.

With carbenicillin at $20 \times$ m.i.c., the majority of cells showed uniform exponential growth with doubling times ranging from 20 to $26 \mathrm{~min}$ and this rate remained constant up to the time of lysis 60 to $96 \mathrm{~min}$ after addition of the antibiotic. However, a small proportion of cells showed slower rates of growth with doubling times ranging from 28 to 34 min and these cells also lysed slightly sooner. Localized swellings were not observed in cells grown in the presence of carbenicillin.

At $40 \times$ m.i.c., carbenicillin caused rapid lysis and the majority of cells showed wall rupture within 20 to $25 \mathrm{~min}$ of addition of the antibiotic. Abnormal cell elongation had not occurred by this time and meaningful measurements of the rate of growth over this period were not possible.

\section{Effect of ampicillin}

At $0.5 \times$ m.i.c. ampicillin completely inhibited cell division and the resulting filaments grew at a uniform exponential rate with a doubling time ranging from 20 to 24 min with a mean of $20.9 \mathrm{~min}$. The majority of these filaments lysed between 97 and $>117 \mathrm{~min}$ after 


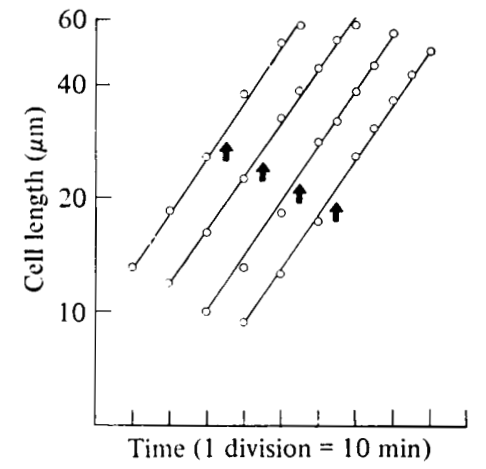

Fig. 3

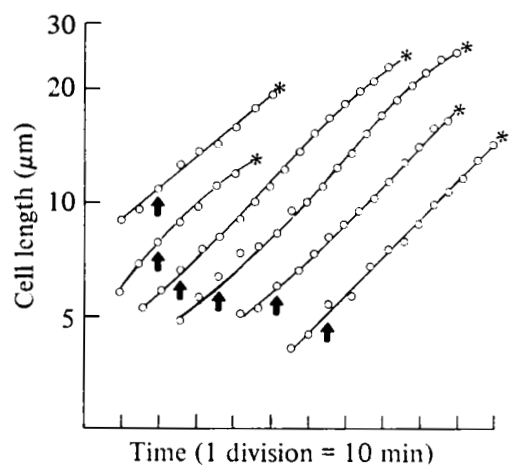

Fig. 4

Figs 3 and 4. Rate of cell growth of E. coli in the presence of carbenicillin (Fig. 3) and ampicillin (Fig. 4) each at $10 \mu \mathrm{g} \mathrm{ml}^{-1}$ ( $2 \times$ m.i.c.). Arrows indicate the times $60 \mathrm{~min}$ (Fig. 3) and $30 \mathrm{~min}$ (Fig. 4) after addition of antibiotic. $*$ denotes the time of lysis.

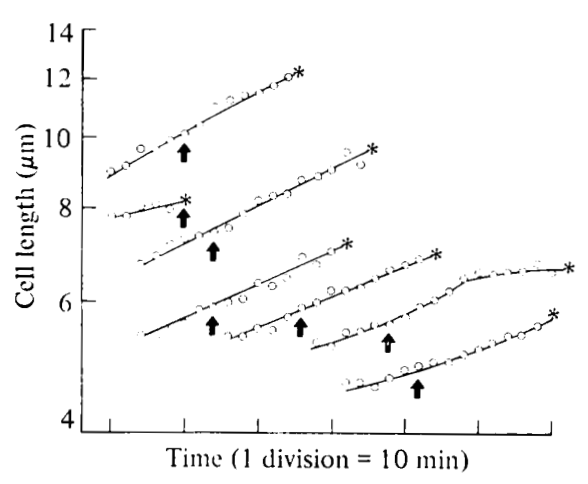

Fig. 5

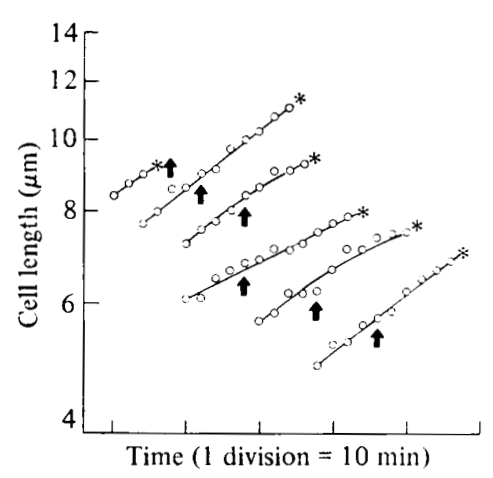

Fig. 6

Figs 5 and 6 Rate of cell growth of $E$. coli in the presence of amoxycillin (Fig. 5) and cephaloridine (Fig. 6) each at $10 \mu \mathrm{g} \mathrm{ml}^{-1}(2 \times \mathrm{m}$.i.c.). Arrows indicate the times $30 \mathrm{~min}$ after addition of antibiotic. $*$ denotes the time of lysis.

addition of the drug. In many of the cells small localized swellings were observed usually at the mid-point of the filament.

Results are shown in Fig. 4 for the effect of ampicillin at a concentration of $2 \times$ m.i.c. While generally following an exponential course the rate of growth was not as uniform as seen with cephalexin or carbenicillin and in a number of cases a slightly sigmoid growth curve was apparent though without any marked change in rate prior to cell wall rupture and lysis. Taking each cell length from the time of first measurement to the time of lysis, the doubling times for the cells shown in Fig. 4 ranged from 30 to $36 \mathrm{~min}$ with a mean of $31 \cdot 8$ min. These cells all lysed between 55 and $95 \mathrm{~min}$ after addition of the drug and localized bulges or collars were observed in the majority of them shortly after addition of the antibiotic.

In the presence of ampicillin at $20 \times$ m.i.c. the cells grew at a relatively uniform exponential rate up to the time of lysis with a doubling time ranging from 35 to 50 min and a mean of $40 \mathrm{~min}$. Lysis occurred rapidly, between 34 and $54 \mathrm{~min}$ after addition of the antibiotic with a mean of $43 \mathrm{~min}$.

\section{Effect of amoxycillin}

In the presence of amoxycillin at $2 \times$ m.i.c., growth generally followed an exponential course though some cells showed a slightly sigmoid curve (Fig. 5). Taking the increase in cell 
Table 1. Effect of cephalexin, carbenicillin, ampicillin, amoxycillin and cephaloridine on growth of $E$. coli

Values given are means with the range in parentheses. Between four and eight bacteria were measured for each antibiotic at each concentration.

Antibiotic and concn

Cephalexin $2 \times$ m.i.c.

$100 \times$ m.i.c.

$500 \times$ m.i.c.

Carbenicillin

$2 \times$ m.i.c.

$20 \times$ m.i.c.

$40 \times$ m.i.c.

Ampicillin

$0.5 \times$ m.i.c.

$2 \times$ m.i.c.

$20 \times$ m.i.c.

Amoxycillin

$2 \times$ m.i.c.

Cephaloridine

$2 \times$ m.i.c.

Normal dividing cells in absence of antibiotic
Cell length doubling time (min)

$\begin{array}{ll}23 \cdot 9 & (23-25) \\ 29 \cdot 5 & (22-54)\end{array}$

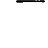

$20.7 \quad(20-22)$

$24 \cdot 7 \quad(20-34)$

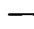

$\begin{array}{ll}20 \cdot 9 & (20-24) \\ 31 \cdot 8 & (30-36) \\ 40 \cdot 0 & (35-50)\end{array}$

$64.6 \quad(54-78)$

$44 \cdot 3 \quad(38-60)$

22
Cell length at time of lysis $(\mu \mathrm{m})$

$\begin{array}{ll}75 & (60-100) \\ 26 \cdot 9 & (12 \cdot 2-45) \\ <8 \cdot 0 & \end{array}$

$>52 \quad(>50->57)$

$32 \quad(11 \cdot 5-57)$

$<8 \cdot 0$

$\begin{array}{rlcl}>35 & (>22->55) & >112 & (97->117) \\ 18 \cdot 8 & (12-25) & 74 \cdot 8 & (55-95) \\ 5 \cdot 9 & (4 \cdot 5-8 \cdot 1) & 43 & (34-54)\end{array}$

$8 \cdot 0 \quad(5 \cdot 7-12 \cdot 1)$

$8 \cdot 2 \quad(6 \cdot 7-11 \cdot 2)$

$4 \cdot 5^{*}$

* Mean cell length of population.

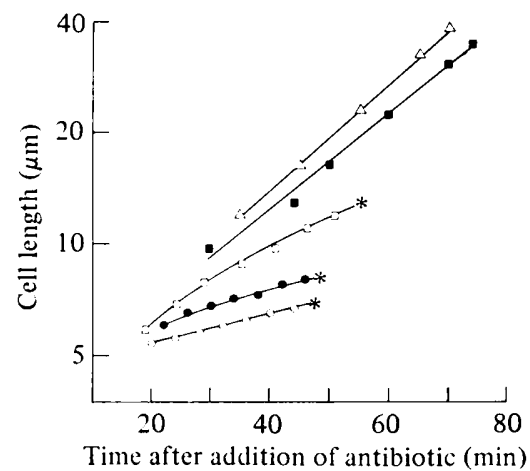

$46 \cdot 8 \quad(30-54)$

Time of lysis after addition of antibiotic (min)

$$
121 \quad(110-134)
$$

$\begin{array}{ll} & 97 \cdot 2 \quad(66-176) \\ < & 30\end{array}$

$142 \quad(130-150)$

$75 \cdot 7 \quad(52-96)$

$<25$

$40.6 \quad(28-46)$
Time after addition of antibiotic ( $\mathrm{min})$

Fig. 7. Rate of cell growth of $E$. coli in the presence of carbenicillin $(\triangle)$, cephalexin $(\square)$, ampicillin $(\square)$, cephaloridine $(\bigcirc)$ and amoxycillin $(\bigcirc)$ each at $2 \times$ m.i.c. $*$ denotes the time of lysis.

length over the total period of measurement the doubling times ranged from 54 to $78 \mathrm{~min}$ with a mean of $64.6 \mathrm{~min}$. The majority of the cells lysed abruptly without any preceding marked change in growth. On the other hand, in a proportion of them the rate of growth decreased appreciably some time prior to cell wall rupture. Cells lysed between 30 and 54 min after the addition of the antibiotic.

\section{Effect of cephaloridine}

With cephaloridine at $2 \times$ m.i.c., growth occurred at a uniform exponential rate up to the time of lysis with a doubling time of 38 to $60 \mathrm{~min}$ and a mean of $44.3 \mathrm{~min}$ (Fig. 6). As in the case of amoxycillin at $2 \times$ m.i.c., in the majority of cells growth remained constant up to the 
time of sudden lysis, but in a small proportion of them the rate of growth decreased some time prior to cell wall rupture. Cells lysed 28 to $46 \mathrm{~min}$ after addition of the antibiotic.

A summary of the results on the effect of the different $\beta$-lactams on the rate of cell growth, the time at which lysis occurred and the cell length at the time of lysis is presented in Table 1. Representative examples of cells are also shown in Fig. 7, for comparative purposes, illustrating the effect on growth rate of all five antibiotics tested, each at $2 \times$ m.i.c.

\section{DISCUSSION}

The penicillins and cephalosporins are generally believed to act, directly or indirectly, by inhibiting the synthesis of murein, an essential component of the cell wall. However, in the presence of cephalexin or carbenicillin at concentrations in excess of the m.i.c., although septation was inhibited completely, growth of $E$. coli continued giving rise to filamentous cells. These filaments eventually lysed and this may have resulted from a localized effect on murein synthesis, or murein hydrolysis, at the division site as has been suggested by Schwarz et al. (1969). However, the results presented here show that prior to the lysis of these filaments the rate of increase in cell length was unaffected by the antibiotic. In support of these results Mirelman et al. $(1976,1977)$ showed that in filamentous cells of $E$. coli grown in the presence of cephalexin there was no diminution in the rate of incorporation of newly synthesized murein into the wall, nor was there any diminution in transpeptidase activity, although there was a marked inhibition of carboxypeptidase activity. Nozaki et al. (1979) have also shown that cephalexin does not markedly inhibit overall murein synthesis or the degree of cross-linking in $E$. coli at concentrations slightly in excess of the m.i.c. On the other hand, inhibition of murein synthesis and cross-linking was observed with cephaloridine at the m.i.c.

Although low concentrations of both cephalexin and carbenicillin did not inhibit cell growth, a marked effect on the rate of growth was observed in the present study with these antibiotics at higher concentrations. Under these conditions the cell length doubling time was increased significantly and the cells lysed much sooner after addition of the drug; indeed, at sufficiently high concentrations, lysis occurred with cephalexin just as rapidly as it did with amoxycillin or cephaloridine. The effect of cephalexin and carbenicillin on growth and speed of lysis is therefore concentration-dependent. This is also in agreement with biochemical studies (Oka \& Fujita, 1978; Nozaki et al., 1979) which showed significant inhibition of murein synthesis and transpeptidase activity by cephalexin provided the antibiotic was present at high concentration.

In contrast to the results obtained with cephalexin and carbenicillin, the exposure of $E$. coli to ampicillin, at concentrations slightly in excess of the m.i.c., resulted in a significant diminution in the rate of cell growth and this was accompanied by an earlier onset of lysis. With amoxycillin and cephaloridine these effects were even more marked. Under these conditions cell wall rupture in $E$. coli was observed to occur at the middle of the cell corresponding to the potential site of division. In filaments, lysis also occurred at a point where septation would normally have taken place. Similar observations have been reported previously (Schwarz et al., 1969; Donachie \& Begg, 1970; Greenwood \& O'Grady, 1973) and it has been suggested (Weidel \& Pelzer, 1964; Schwarz et al., 1969) that cell wall rupture occurs as a result of an imbalance between murein synthesis and murein hydrolysis at the site of division giving rise to a localized weakness in the wall. If this is so, it might be considered that $\beta$-lactams which cause rapid lysis result in a more profound weakness, leading to earlier rupture of the wall. Similarly, it might be suggested that rapid lysis at very high concentrations of cephalexin is due to a more rapid or more complete derangement at the division site than is the case at relatively low concentrations. However, the results of studies on penicillin-binding proteins (Spratt, 1976, 1977; Tamaki et al., 1977; Suzuki et al., 1979) suggest that different targets are involved in filament formation, on the one hand, and 
rapid lysis, on the other, rather than a different degree of effect on one and the same target. In the work reported here the dose/response relationship with both cephalexin and carbenicillin also suggests that different targets are involved in the different morphological effects. With cephalexin a 50-fold increase in concentration from $2 \times$ m.i.c. to $100 \times$ m.i.c. resulted in only slightly diminished filament formation, and only a slightly earlier onset of lysis. With further increase in concentration to $500 \times$ m.i.c. lysis occurred extremely rapidly with negligible cell elongation. Similarly, with carbenicillin a 10 -fold increase in concentration from $2 \times$ m.i.c. to $20 \times$ m.i.c. was accompanied by only slightly less filament formation, but with a further increase to $40 \times$ m.i.c. lysis occurred very rapidly with negligible elongation. These results suggest that at the higher concentrations a different mechanism or target is involved and that a consequence of this is inhibition of growth, i.e. inhibition of extension of the cell wall cylinder. The results presented here show that $\beta$-lactams which result in rapid lysis do cause inhibition in the rate of cell growth. Inhibition of growth, and therefore inhibition of increase in cell volume, would be expected to give rise to an increase in internal cell pressure. Under such circumstances a given degree of weakness at the division site might now be revealed sooner by rupture of the wall. The differences between the delayed lysis of filaments and the early lysis of short cells therefore might be due not to a difference in the degree of weakness of the wall but to a difference in the internal pressure causing such a weakness to fail.

\section{REFERENCES}

Donachie, W. D. \& BegG, K. J. (1970). Growth of the bacterial cell. Nature, London 227, 1220-1224.

Gardner, A. D. (1940). Morphological effects of penicillin on bacteria. Nature, London 146, 837838.

Greenwood, D. \& O'Grady, F. (1973). Comparison of the responses of Escherichia coli and Proteus mirabilis to seven $\beta$-lactam antibiotics. Journal of Infectious Diseases 128, 211-221.

Mirelman, D., Yashouv-Gan, Y. \& Schwarz, U. (1976). Peptidoglycan biosynthesis in a thermosensitive division mutant of Escherichia coli. Biochemistry 15, 1781-1790.

Mirelman, D., Yashouv-Gan, Y. \& Schwarz, U. (1977). Regulation of murein biosynthesis and septum formation in filamentous cells of Escherichia coli PAT 84. Journal of Bacteriology 129, 1593-1600.

Nozaki, Y., IMAda, A. \& Yoneda, M. (1979). SCE129 , a new potent cephalosporin with high affinity for penicillin-binding proteins 1 and 3 of Escherichia coli. Antimicrobial Agents and Chemotherapy 15, 20-27.

OkA, T. \& Fujita, N. (1978). Effect of $\beta$-lactam antibiotics on in vitro peptidoglycan crosslinking by a particulate fraction from Escherichia coli K12 and Bacillus megaterium K.M. Antimicrobial Agents and Chemotherapy 14, 625-627.

Rolinson, G. N., Macdonald, A. C. \& Wilson, D. A. (1977). Bactericidal action of $\beta$-lactam antibiotics on $E$. coli with particular reference to ampicillin and amoxycillin. Journal of Antimicrobial Chemotherapy 3, 541-553.

Schwarz, U., Asmus, A. \& Frank, H. (1969).
Autolytic enzymes and cell division of Escherichia coli. Journal of Molecular Biology 41, 419-429.

SpRatT, B. G. (1976). Distinct penicillin binding proteins involved in the division, elongation, and shape of Escherichia coli K12. Proceedings of the National Academy of Sciences of the United States of America 72, 2999-3003.

SpRatT, B. G. (1977). Temperature-sensitive cell division mutants of Escherichia coli with thermolabile penicillin-binding proteins. Journal of Bacteriology 131, 293-305.

Strominger, J. L. (1973). The actions of penicillin and other antibiotics on bacterial cell wall synthesis. Johns Hopkins Medical Journal 133, 63-81.

Suzuki, H., Nishimura, Y. \& Hirota, Y. (1979). On the process of cellular division in Escherichia coli: a series of mutants of $E$. coli altered in the penicillin-binding proteins. Proceedings of the National Academy of Sciences of the United States of America 75, 664-668.

Tamaki, S., Nakajima, S. \& Matsuhashi, M. (1977). Thermosensitive mutation in Escherichia coli simultaneously causing defects in penicillinbinding protein-1Bs and in enzyme activity for peptidoglycan synthesis in vitro. Proceedings of the National Academy of Sciences of the United States of America 74, 5472-5476.

Tomasz, A. (1979). From penicillin-binding proteins to the lysis and death of bacteria: a 1979 view. Reviews of Infectiol:s Diseases 1, 434-467.

Weidel, W. \& Pelzer, H. (1964). Bagshaped macromolecules - a new outlook on bacterial cell walls. Advances in Enzymology 26, 193-232. 